\title{
For whom is it worth lying? Prosocial lies in school children
}

\author{
Daiane Araujo de Arruda ${ }^{1}$ \\ Debora Hollanda Souza ${ }^{1}$
}

\begin{abstract}
A prosocial lie is a false statement intended to help and not to harm someone. The present study investigated possible effects of age and culture in 97 Brazilian children's responses ( 7 to 11 years of age) in a prosocial lying task, designed for a previous study with Canadian and Chinese children. The task consisted in presenting four dilemmas followed by questions about what children should do: tell the truth or lie to protect the self, a friend or a group? No effect of age was found for the lying scores, but the lying-forfriend scores were significantly higher than the lying-for-self and lying-for-collective scores. This pattern of results suggests that, in contrast to Chinese and Canadian children, Brazilian children find it more worthwhile to tell a lie that protects a friend than a lie that protects self-interests or those of a group.
\end{abstract}

Keywords: lies, school children, culture

\section{Por quem vale a pena Mentir? A mentira Pró-Social em crianças escolares}

Resumo: A mentira pró-social é uma declaração falsa contada com o objetivo de ajudar e não prejudicar alguém. Este estudo teve por objetivo investigar possíveis efeitos de idade e cultura sobre as respostas de 97 crianças brasileiras ( 7 a 11 anos) em uma tarefa de mentira pró-social, criada para um estudo prévio com crianças canadenses e chinesas. A tarefa consistiu na apresentação de quatro dilemas seguidos de perguntas sobre como as crianças agiriam: contariam a verdade ou mentiriam para proteger a si mesmas, um amigo ou o grupo? Não foi encontrado um efeito de idade sobre os escores de mentira, mas os escores de mentira para beneficiar um amigo foram significativamente maiores que os escores mentir-por-si e mentir-pelo-coletivo. Esse padrão de resultados sugere que, em contraste às crianças chinesas e canadenses, para as brasileiras, vale mais a pena contar uma mentira para proteger um amigo do que para proteger interesses próprios ou coletivos.

Palavras-chave: mentira, crianças em idade escolar, cultura

\section{¿Por quién conviene mentir? La mentira Prosocial en escolares}

Resumen: La mentira prosocial es una declaración falsa con el fin de ayudar y no perjudicar a alguien. Este estudio pretende investigar la posible influencia de la edad y la cultura en las respuestas de 97 niños brasileños (de 7 a 11 años) en una tarea de mentira prosocial diseñada en un estudio previo con niños canadienses y chinos. La tarea consistió en presentar cuatro dilemas seguidos de preguntas sobre cómo actuarían los niños: diría la verdad o diría una mentira para proteger a sí mismo, a un amigo o al grupo. No se encontró ninguna influencia de la edad en los puntajes de mentira, sin embargo, los puntajes de mentira para beneficiar a un amigo fueron los más altos significativamente que los puntajes de mentir por sí mismo y mentir por el colectivo. Este patrón de resultados evidencia que, a diferencia de los niños chinos y canadienses, los niños brasileños consideran que vale más la pena mentir para proteger a un amigo que para proteger a sus propios intereses o del colectivo.

Palabras clave: mentira, niños en edad escolar, cultura

${ }^{1}$ Universidade Federal de São Carlos, São Carlos-SP, Brazil

Article derived from research (Scientific Initiation) conducted by the first author and supervised by the second author in 2014, at Universidade Federal de São Carlos. Research and manuscript preparation were funded by grant \# 2013/08891-1 (to the first author) from Fundação de Amparo à Pesquisa do Estado de São Paulo/FAPESP and by Coordenação de Aperfeiçoamento de Pessoal de Nível Superior - Brasil (CAPES) - Finance Code 001. This study is part of the research program of the National Institute of Science and Technology on Behavior, Cognition, and Teaching, supported by grants from the Brazilian National Research Council - CNPq (Grants \# 573972/2008-7 and 465686/2014-1) and Fundação de Amparo à Pesquisa do Estado de São Paulo - FAPESP (Grants \# 2008/57705-8 and 2014/50909-8).

Correspondence address: Daiane Araujo de Arruda. Universidade Federal de São Carlos. Programa de Pós-Graduação em Psicologia. Rodovia Washington Luís, Km 235, São Carlos-SP, Brasil. CEP 13.565-905. E-mail: daia.hiane@gmail.com
Children start forming opinions about other people's behaviors during their early years (Heyman, 2013). Twoyear-old children already use terms that refer to mental states such as "know", "think", "happy" and "sad" (Bartsch \& Wellman, 1997), and they police violations to social rules (Rakoczy, Warneken, \& Tomasello, 2008; Ross \& Den BakLammers, 1998). Even pre-verbal children already evaluate individuals based on positive or negative behavior directed at others (Hamlin, Wynn, \& Bloom, 2007).

The psychological processes that allow us to understand and formulate explanations on different social situations are studied by the field of social cognition (Rabelo, Hess, \& Pilati, 2012; Winkielman \& Schooler, 2009). 
The development of this social understanding is one of the most important milestones of cognitive development (Miller, 2019) as it includes both beliefs about oneself (such as our own desires and emotions) and about others.

Recent studies have not only investigated the development of social cognition but also its relationship with moral development (Lee, 2013). Among the various aspects of the relationship between these two variables, one in particular has been studied since the beginning of this study field in Psychology: children's understanding of lies. According to Lee (2013), the founders of this field, like Darwin, Hall, Binet and Piaget, discussed and conducted studies on children's lying. In the past few years, several scholars investigated different aspects of children's understanding of lying: the appropriateness of the participation of children as witnesses in court (Evans, Stolzenberg, Lee, \& Lyon, 2014), the level of trust in adults who lie (Fu, Heyman, Chen, Liu, \& Lee, 2015), and the neural mechanisms underlying the behavior of lying (Ding, Gao, Fu, \& Lee, 2012; Ding, Sai, Fu, Liu, \& Lee, 2013).

By definition, lying is claiming to be true what is known to be false, that is, it means intentionally inducing a false belief in another person (Lee, 2013). At first, lying seems reprehensible, as it can be seen in the maxims: "One should never lie", or "Lying is nasty", after all, "A lying person is not trustworthy." At the same time, however, children testify to situations when lying is considered appropriate. A mother, for example, teaches her daughter, on her $4^{\text {th }}$ birthday, that she should not tell her uncles that she hated receiving clothes as a birthday gift instead of toys, and that she should say "Thank you! I liked it very much", even if it is a lie. Many parents believe that their children's lying behavior is admissible only when they have a prosocial function, for instance, to protect someone (Lavoie, Leduc, Crossman, \& Talwar, 2016).

Such lie, aimed to obtain social acceptance, is called a prosocial lie. Bok (1978) defines it as a false statement told without malice or malicious intent. More specifically, prosocial lying serves two functions: (1) to avoid hurting the listener's feelings and (2) to avoid negative reactions from the listener if the truth is told (Talwar \& Lee, 2002). Prosocial lying, therefore, can be classified as a type of prosocial behavior, expressed by the action of lying, which is largely reinforced. Individuals who benefit or protect another from suffering by lying are perceived as educated and caring, for example.

According to Kuhlmeier, Dunfield and O'Neill (2014), prosocial behavior can be defined as the intermediate and beneficial actions that are preceded by direct observation or inference of a negative state in another person. It includes actions of sharing, helping or trying to comfort someone that may be motivated by: (a) concern for other people; (b) receiving approval or some type of reward; (c) a desire to be in accordance with social norms; or (d) a feeling of "mission accomplished" (Eisenberg, Eggum-Wilkens, \& Spinrad, 2015).

According to Dunfield, Kuhlmeier, O'connell and Kelley (2011), there is no consensus on how prosocial behavior manifests throughout child development. Many researchers have suggested that the frequency and complexity of prosocial behaviors would increase as children grew older and developed more advanced social cognitive abilities. However, other researchers believe that after initial emergence, prosocial behavior decreases as they become more regulated and selective.

There is evidence that prosocial behavior is associated with theory-of-mind development, although the magnitude of this association is not strong (Imuta, Henry, Slaughter, Selcuk, \& Rufman, 2016). However, research on sociocognitive development has shown that children are only capable of lying when they have a more sophisticated theory of mind, that is, when they start to understand that a person can have a belief about reality that is different from their own, which would occur, according to studies in the field, between 4 and 5 years of age (Wellman, 2014).

According to Talwar and Lee (2002), 3-year-old children are already capable of telling prosocial lies successfully, despite not being able to explain the reasons why they lied. Starting at age 7, they are capable of lying with the intention of improving someone else's mood or to make someone feel better (Warneken \& Orlins, 2015). However, according to Bergstrom, Najdowski, Alvarado and Tarbox (2016), children diagnosed with Autism Spectrum Disorder have difficulty understanding and telling social lies, which can hurt certain social situations like keeping secrets, surprising someone, playing and bluffing in games. Such difficulties illustrate the importance of this kind of lie in child development.

There is recent evidence of effects of the cultural environment on different aspects of prosocial behavior, including prosocial lying. Loke, Heyman, Itakura, Toriyama and Lee (2014), for example, found that both Japanese and U.S. children $(7,9$, and 11 years) find it appropriate to tell the teacher the truth when a classmate commits a serious transgression (e.g., stealing money from another classmate). However, in contrast to U.S. children, Japanese children consider it more appropriate to also disclose minor transgressions (e.g., the classmate brought the wrong material to class). A study by Fu, $\mathrm{Xu}$, Cameron, Heyman and Lee (2007), in turn, indicated that Chinese children lie more in favor of a social group, whereas Canadian children lie more to favor a single individual.

Fu et al. (2007) conducted four experiments with Chinese and Canadian children aged 7, 9 and 11 years. In the first and second experiments, some stories (dilemmas) were told to children who should respond as if they were the story characters themselves, telling what they would do if they were in the same situation. During the first experiment, the participant had to say which choice they would make if they had to decide between helping a friend (harming the group) or benefiting the group (harming their friend), whereas in the second experiment, the dilemmas involved choices between lying or not to benefit oneself and harm the group (or vice-versa). The other two experiments consisted in the presentation of the dilemmas, followed by the narration of what the character decided to do (lie or tell the truth in favor of an individual or a group), as well as the request for an evaluation by the child concerning what the character had done. The third experiment required children to evaluate a character who lies or does not lie for a friend to the detriment of the group, and in the fourth, 
children had to evaluate a character who lies or does not lie to benefit oneself or a group.

Overall, results revealed a cultural effect, as Chinese participants tended to protect the group more, regardless of the age group, whereas Canadian participants protected their friend and themselves more. In other words, the cultural environment seems to play an important role in the decision between lying and telling the truth as well as in moral assessments; after all, child development cannot be understood separately from its social and cultural context. More specifically, Chinese children considered whether they were useful or harmful to the collective, whereas Canadian children emphasized the protection of their personal rights, their individual interests and achievements, as well as the importance of their own goals.

A possible explanation for the differences in the pattern of choices for the two groups of children is related to the individualistic culture versus collectivistic culture dichotomy. According to Brewer and Chen (2007), individualistic cultures value autonomy, emotional independence, individual initiative, and the right to privacy. On the other hand, collectivistic cultures value collective identity, solidarity, sharing, duties and group decisions. However, according to these authors, many instruments designed to assess behaviors specific to collectivistic/individualistic cultures do not consider the difference between the needs of a closer and smaller social group, such as the family, and a larger social group, such as the country or the company in which someone works. Additionally, each individual handles unique dilemmas that require specific moral judgments and choices in their daily lives. From this perspective, individuals would act by combining general elements of both the individualistic type (their own interests) and the collectivistic type (based on the knowledge provided by culture) to solve their problems, eliciting a new way of relating to the social world (Wainryb \& Recchia, 2014).

Another study investigating cultural differences in prosocial behavior included participants from 23 major cities around the world (Levine, Norenzayan, \& Philbrick, 2001). Participants were exposed to three situations that always involved an actor pretending to be someone who needed help. In the first situation, the actor played a pedestrian who drops a pen. In the second, the actor played a pedestrian with a limping leg who was trying to reach a pile of magazines that had fallen on the floor. Lastly, in the third situation, the actor played a blind person trying to cross the street. The authors then recorded the number of people (in each of these countries) who were willing to help the individual (the actor) who needed help. According to the results of the study, Brazilians are in $1^{\text {st }}$ place (among the selected countries) in the ranking of helping strangers behavior, evidence that Brazilian culture encourages prosocial behaviors.

At the same time, in Brazilian culture, the phenomenon known as "jeitinho brasileiro" (literally: Brazilian way of doing things) reveals a form of acting in the world that includes circumventing previously stipulated rules, procedures, or techniques, but which is widely accepted in the face of unexpected, difficult or complex situations, using improvisation, creativity, interpersonal empathy and cordiality (Ferreira, Fischer, Porto, Pilati, \& Milfont, 2012). By making use of this "jeitinho", an individual violates moral values to solve a problem and achieve a personal goal. According to Motta and Alcadipani (1999, p. 1), it is used for "bending rules that, if taken into account, would make it impossible to perform the action intended by the person who requests it, thus valuing personal values to the detriment of universal ones". Thus, Brazilians would be expected to lie in favor of themselves or their friends.

A review of the Developmental Psychology literature, however, indicates that the number of Brazilian studies on the behavior of lying in children is scarce, as well as studies on prosocial lying. Considering the evidence of cultural differences in lying behavior (Fu et al., 2007; Loke et al., 2014), it is possible that the practice of lying in Brazilian society influences the behavior and choices of children.

The present study investigated the possible effects of age and culture on the responses of 97 Brazilian children (7- to 11-year-olds) in a prosocial lying-related task created for a previous study with Canadian and Chinese children. Additionally, the present study aimed to test the effect of an important variable on this choice: who will benefit from this lie (if only one person or a social group to which the child belongs). In two different experimental conditions, it was possible to vary the individual to be benefited (who would be in opposition to the group). In the first experimental condition, the dilemmas always contrasted the interests of the group and those of a friend of the character; in the second experimental condition, the interests of the group were contrasted to the interests of the character. Such dilemmas were presented in an adapted version of the prosocial lying task created by $\mathrm{Fu}$ et al. (2007) for a study conducted with Canadian and Chinese children. Thus, the study also allowed a cultural comparison between the data obtained in the original study, with Chinese and Canadian children, and that obtained in the present study, with a sample of Brazilian school age children.

\section{Method}

The present study has a cross-sectional design, as it investigates possible differences in the pattern of responses of Brazilian children from three different age groups. Comparisons between the results found in the original study with Chinese and Canadian children and those found with Brazilian children in the present study were also made.

\section{Participants}

Ninety-seven children participated in this study. In order to test the possible effects of the two variables of interest (age and beneficiary), participants were randomly distributed into two different experimental conditions, and each child participated in only one of the two experimental conditions.

In Experimental Condition 1, children heard dilemmas that required a choice between telling the truth and lying, and their choice could favor a friend or a group to which 
they belonged. Fifty children were assigned to Experimental Condition 1: 18 were $2^{\text {nd }}$ graders in an Elementary School ( $M=7.86$ years, $S D=0.40 ; 8$ boys, 10 girls $), 14$ were $4^{\text {th }}$ graders $(M=10.44$ years, $S D=0,39 ; 4$ boys, 10 girls $)$ and 18 children were $6^{\text {th }}$ graders $(M=11.73$ years, $S D=0.51 ; 6$ boys, 12 girls).

In Experimental Condition 2, children heard dilemmas that involved the choice between lying or telling the truth, favoring themselves or the group to which they belonged. Forty-seven children were assigned to this condition: 19 children from $2^{\text {nd }}$ grade $(M=8.05$ years, $S D=0.44 ; 9$ boys, 10 girls $), 15$ children were $4^{\text {th }}$ graders $(M=10.35$ years, $S D=0.46 ; 4$ boys and 11 girls) and 13 children were $6^{\text {th }}$ graders ( $M=11.70$ years, $S D=0.47 ; 6$ boys, 7 girls).

Participants were students from two municipal schools located in a town in the state of São Paulo that serve middleclass families. Data collection started as soon as it was authorized by the City Department of Education, by the board of the two schools and by the teachers responsible for the students. Children whose parents signed the consent form were asked to participate in the research and only those who signed the assent form effectively participated.

\section{Instruments}

A translated and adapted version of a prosocial lying task (Fu et al., 2007) was used to evaluate how children of different ages understand the use of lying (prosocial or non-prosocial) in different contexts. The task consists in the presentation of different stories during which one of the characters needs to solve a dilemma: tell the truth or lie to protect himself, a friend or a collective (e.g., their classmates). The stories were translated from English to Brazilian Portuguese by the two researchers independently, after consent from the authors of the original article, who sent a copy of the original stories by mail. The two researchers are proficient in English (the second is bilingual) and both are familiar with the subject.

It is worth noting that this task is not a psychological test, but rather an instrument to evaluate what children of different ages think about the use of lying when the beneficiary of it is a single individual (themselves or a friend) or a group. Thus, there is no record of a study on the psychometric properties or the validation of this instrument in its original version or in the translated/adapted version in Brazilian Portuguese.

Adaptation was necessary because one of the dilemmas involved an activity ("singing in a choir") that is not common in Brazilian public schools. Thus, this activity was replaced by "dodgeball" in the present study since it is also a competition and this substitution does not change the purpose of the story. Additionally, the names of the characters were substituted for names that were more familiar to children (for example, "André" instead of "Mike"). Excluding the aforementioned changes, the dilemmas did not diverge in any other aspect in comparison to the dilemmas presented in the procedure by Fu et al. (2007).

The four dilemmas of each experimental condition specifically require the child to decide whether or not to: (1) lie to help a single individual and harm the collective;
(2) lie to help the collective and harm an individual; (3) Tell the truth to help an individual and harm the collective; and (4) tell the truth to help the collective and harm an individual.

As stated earlier, the dilemmas vary according to the experimental condition in respect to the "individual" to be benefited/harmed (a friend or the child/character), however, they all require the same kind of decision: how the child would act if she were the character of the story/dilemma. The following story/dilemma is presented in Experimental Condition 1 and it involves a choice between telling the truth to help a friend and harming the collective: "Bianca was close friends with Guilherme, who was a member of the school basketball team. Guilherme was the team's best player and his presence in the team was essential to the their success, but Guilherme was unhappy because he preferred playing soccer. Bianca found out that there was an opening for a new player on the soccer team. Then Bianca thought to herself: "if I tell Guilherme about the opening, he will leave our team and we will not win games anymore; but Guilherme is my friend, and if I tell him, he will join the soccer team and be happier." Guilherme asked Bianca if she knew of any new openings in other teams. If you were Bianca, what would you do? Would you help your friend Guilherme and tell him that there is an opening on the soccer team? Or would you help your basketball team and tell him that there is no opening on the soccer team?".

An example of the history/dilemma of experimental condition 2 is presented next. This one involves a choice between telling the truth to help the child and harm the collective: "Bianca is a member of the school basketball team. Bianca was the team's best player, and because of her, the team always won every game. There was a very important game one evening, but Bianca had hurt her arm and she wasn't sure if she could play. Then Bianca thought to herself: "If I play, I may hurt my arm. But if I don't play tonight, the basketball team may not win this important game." The coach asked Bianca, “Are you okay to play tonight?". If you were Bianca, what would you do? Would you take care of your arm and tell the coach that you're not okay to play because you hurt your arm? Or would you help your team and tell the coach that you're okay to play?".

It is worth noting that each dilemma was accompanied by two illustrations representing different moments of the story, thus facilitating children's understanding and keeping their attention on the task (similar illustrations were used in the study by Fu et al., 2007).

\section{Procedure}

Data collection. Data collection was conducted in the premises of the schools where participants were recruited, in well-lit rooms with tables and chairs, in addition to the material used in the procedure: stories (with their respective illustrations), material for annotation and a smartphone to record the audio of children's responses.

After a period of familiarization between the experimenter and the children, each child was individually escorted to the experiment room. The experimenter explained 
to the participants what would happen and clarified that, in case of doubt, the child could ask questions. Next, the experimenter read the four stories/dilemmas to the child. The order in which the stories were presented was counterbalanced. Soon after the presentation of each story, the experimenter asked what the child would do in that situation, if she were the character and why she would act that way. All answers were recorded in audio and in writing on a note sheet. When the child's participation was completed, the experimenter escorted the child back to the classroom, more specifically, to meet their teacher or teacher assistant.

Data analysis. Data was coded so as to generate three scores for each child: a total lying score, a lying score to protect the collective, a lying score to benefit a single individual (self or friend, depending on the experimental condition). In two of the four dilemmas in Experimental Condition 1, if the child chooses to lie, she benefits the friend; in the other two dilemmas, if she chooses to lie, she benefits the collective. For children in Experimental Condition 2, in two dilemmas, if she chooses to lie, she benefits herself, and if she does the same in the other two dilemmas, she benefits the collective.

Based on this coding system, children in Condition 1 obtained a "lying-for-self" score (2 dilemmas; a score ranging from 0 to 2 points), and a "lying-for-collective" score (2 dilemmas; 0 to 2 points), and those in Condition 2 obtained a "lying-for-self" score (2 dilemmas; 0 to 2 points), and a "lying-for-collective" score ( 2 dilemmas; 0 to 2 points). For example, a child in Experimental Condition 1 would receive a "lying-for-friend" score of 0 if she chose to tell the truth in the two dilemmas in which the lie would benefit the friend; and they would receive a "lying-for-collective" score of 2 if they chose to lie in the two dilemmas in which the lie would benefit the group.

Regardless of the experimental condition, the sum of the two scores mentioned above generated the total lying score, which was called the "amount of lying". Children could have chosen not to lie once ( 0 point), to lie once ( 1 point), twice ( 2 points), thrice ( 3 points), or in all dilemmas (4 points).

The Kolgomorov-Smirnov test revealed that the score distributions in the two experimental conditions were not normal: 1) for condition $1, D(50)=0.28, p<0.05$ for the lying-for-friend score, and $D(50)=0.30, p<0.05$ for the lying-for-collective score; in condition $2, D(47)=0.32, p<$ 0.05 for the lying-for-self score, and $D(47)=0.32, p<0.05$ for the lying-for-collective score. Based on these results, the statistical tests used in this study were non-parametric. The level of significance adopted for all statistical analyses was $5 \%(0.05)$.

\section{Ethical Considerations}

This research was approved by the Ethics Committee of Universidade Federal de São Carlos (UFSCar) (CAAE: 11094212.1.0000.5504).

\section{Results}

The Mann-Whitney test was used to test a possible effect of gender on choices made in response to the dilemmas. No significant difference was found between boys and girls in respect to the scores obtained for both Condition 1 and Condition 2, $p s=\mathrm{n}$. s. Therefore, this variable was removed from subsequent analyses.

\section{Age and beneficiary effects in Experimental Condition 1}

To test for possible effects of age on lying scores in Condition 1, the Kruskal-Wallis test was performed with the following variables: age group ( $2^{\text {nd }}, 4^{\text {th }}$ and $6^{\text {th }}$ graders $)$ and beneficiary of lying (friend vs. collective). The statistical test revealed only a trend toward an effect of age on the lyingfor-collective score, $H(2)=5.15, p=0.07, r=-0.30$. MannWhitney tests, using the Bonferroni correction, revealed a significant difference only between $4^{\text {th }}$ and $6^{\text {th }}$ graders, $U=$ 74.0, $p=0.02, r=-0.38$.

The Wilcoxon test revealed a significant effect of the beneficiary variable, more specifically, children in Condition 1 , regardless of age, lied more to benefit their friend than to benefit the collective, $z=-3.73, p=0.00, r=-0.52$. Figure 1 shows the mean scores and standard errors of lying-for-friend and lying-for-collective for each age group in this condition.

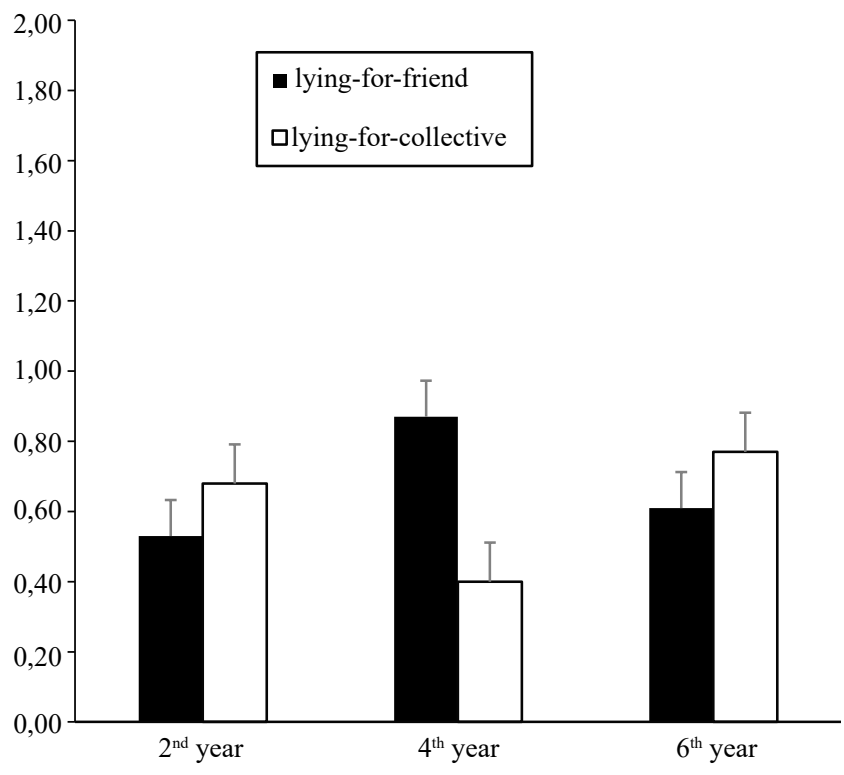

Figure 1. Means and standard error for the scores of lying-for-friend and lying-for-collective by age group (Experimental Condition 1).

\section{Effects of age and beneficiary in Experimental Condition 2}

The Kruskal-Wallis test with, age group $\left(2^{\text {nd }}, 4^{\text {th }}\right.$ and $6^{\text {th }}$ graders) and beneficiary of the lie (the child vs. collective) as variables, did not reveal a significant relationship 
between age and lying-for-collective, $H(2)=3.9, p=0.14$, and between age and lying-for-self, $H(2)=1.6, p=0.45$. The Wilcoxon test did not reveal a significant difference between the lying-for-self and lying-for-collective scores, $z=-0.56, p=0.60$.

Figure 2 shows the means and standard errors of the lying-for-self and lying-for-collective scores for each age group. In this experimental condition, all lying scores were less than 1, that is, most children did not lie more than once when they had to decide between protecting themselves or a social group.

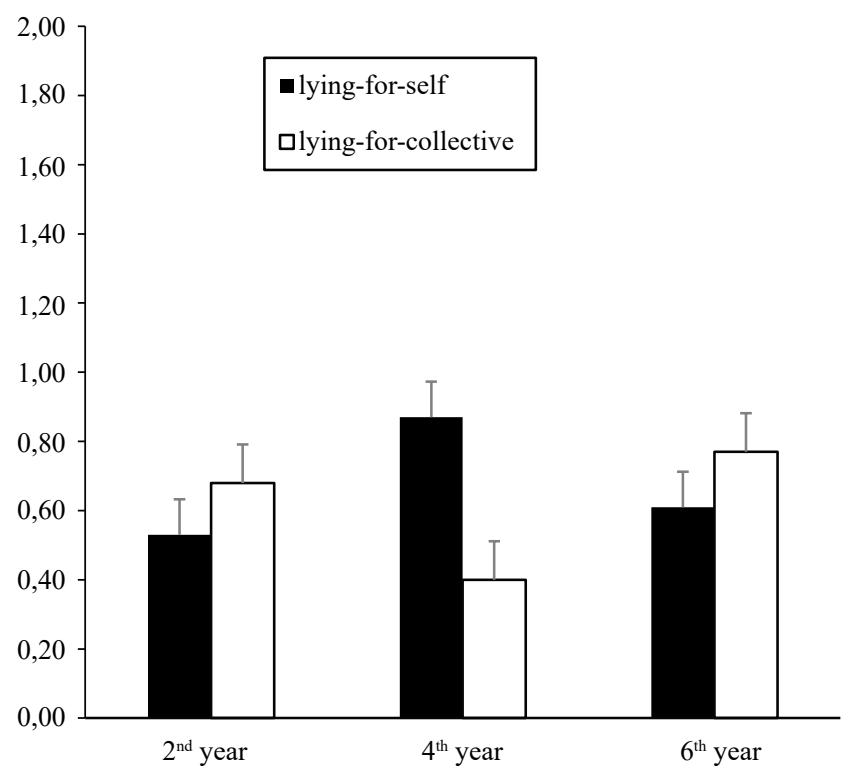

Figure 2. Means and standard error for the scores of lying-for-self and lying-for-collective by age group

(Experimental Condition 2).

\section{The lie and the truth}

A chi-square test revealed a significant difference between the frequency distribution of the total lying scores (range from 0 to 4 points) obtained in condition 1 and those obtained in condition $2, \chi^{2}(4)=15.28, p=0.002$. A much larger number of children in condition 2 chose to always tell the truth $(31.9 \%)$ than in condition $1(4 \%)$. A very limited number of children chose to lie in all four dilemmas $(6 \%$ in condition 1 and $2.1 \%$ in condition 2). When the choice was between benefiting a friend and the collective (condition 1), $60 \%$ of the children chose to lie in two of the four stories, as opposed to $34 \%$ of the children in condition 2, who had to choose between benefiting themselves or the collective.

\section{Discussion}

The main objective of this study was to investigate the possible effects of age and culture on children's responses to dilemmas between telling the truth and prosocial lying. The statistical analyses revealed only a trend toward an age effect on the lying-for-friend score (Experimental Condition 1). More specifically, it is possible that older children ( $6^{\text {th }}$ graders) have a greater inclination toward lying for the sake of a friend (when such interests are opposed to those of a group) than younger children $\left(4^{\text {th }}\right.$ graders). This significant difference in the propensity to lie for the sake of a friend in $4^{\text {th }}$ and $6^{\text {th }}$ graders, if confirmed, goes in the opposite direction of the pattern of results obtained with Chinese children in Experiment 1 by Fu et al. (2007), as this inclination decreased with age. More specifically, 11-year-old Chinese children lied less to benefit the friend than younger ones. On the other hand, Canadian children, in all three age groups, always lied more to benefit a friend than to benefit the group.

The results obtained in condition 2 in the present study suggest that there is no effect of age on the behavior of lying to benefit oneself or to benefit a group. This pattern is also different from that found with Chinese children, given that they showed a stronger inclination to benefit the collective as they grew older. Unlike Brazilian children in this study and Chinese children, Canadian children, regardless of age, always prioritized benefiting themselves to the detriment of the collective.

It is possible that the task of recording developmental changes in prosocial lying is more difficult than it may seem at first. For example, Dunfield et al. (2011) argue that it is difficult to establish whether prosocial behavior increases or decreases with age due to the large number of variables that can affect it (e.g., development of cognitive abilities, selfregulation). Thus, even in a simple situation, such as the ones described in the stories presented, the child may be under the control of different aspects of the dilemma, depending, for example, on their repertoire, past history or even social skills. Future studies should investigate other variables that may explain both individual differences in the propensity to lie prosocially, as well as cultural differences.

When comparing data from the experimental conditions in the present study, it is possible to infer that, for the Brazilian children recruited for this study, the friend is the preferred beneficiary in situations where someone will be harmed by the choice between telling a lie or telling the truth. The frequency distribution analysis of total lying scores also suggests that the children in the present study are more likely to lie when a friend can benefit from the lie, but not as much when choosing to lie to benefit themselves.

Considering the maxim of "not lying", it would be worth telling a lie to protect a friend, but it would not be worth telling a lie to protect one's own interests or the interests of one's group. This trend is consistent with Lavoie et al.'s findings (2016). They interviewed 146 parents in order to assess their beliefs and how they socialize their children about lying. Although most parents in this study told their children that lying is never acceptable, they actually believe that lying is acceptable in certain situations, especially when it serves the role of protecting someone.

Additionally, when one's own interests are confronted with those of the social group, there are some children who choose to protect themselves, whereas others prefer to 
Arruda, D. A., \& Souza, D. H. (2020). For Whom is it Worth Lying?

protect the group. In comparison to Fu et al.'s study (2007), this trend seems to be different from that presented by children in Canada, who choose predominantly to protect themselves, and from children in China, who choose predominantly to protect the social group. Following the discussion of collectivistic and individualistic cultures, Brazilian children don't fit perfectly into either of the two descriptions, given that, in the dilemma context, they would sometimes act in a more individualistic manner (when it is necessary to tell a lie to help a friend), and, at other times, in a more collectivistic manner (when a lie is necessary for their own interests or to respect the interests of the group). This pattern seems to illustrate a mix of elements from both cultures, as proposed by Wainryb and Recchia (2014). Nonetheless, in a similar direction than that followed by $\mathrm{Fu}$ et al. (2007), children's choices (between lying and telling the truth) seem to be influenced by cultural aspects.

It is important to note, however, that children in the present study reported the choice they would make if they were facing the four dilemmas, but this claim does not guarantee that they, in fact, would act as expected in a natural situation. The responses reveal more about their understanding of prosocial lying and about what they think is right or wrong than about their actual behavior. Studies that contemplate the need for a choice made by the participant in a simulated situation (Levine et al., 2001) are a promising direction of research.

In summary, the data seems to suggest that the children in the present study tend to adopt prosocial behavior (helping friends) above their own interests in situations that seem to invite lying. It is possible that prosocial behaviors are valued by Brazilian culture, as suggested by Levine et al. (2001). However, this behavior would be specifically directed at someone close, and not to a stranger in need of help, such as the situations presented in the Levine et al. study. In addition, the Brazilian data from the study by Levine et al. were obtained only in the city of Rio de Janeiro. In turn, the sample of Brazilian children in the present study was representative of a specific population: middle class children, attending a public school in a municipality in the state of São Paulo. As such, statements about the generality of these results should be avoided. At the same time, if we consider the limitation in the scope of the results and the need for caution in the interpretation of these data, the current study has the potential to represent a first and important step for the advancement of research on the development of prosocial lying in Brazilian children and on the possible effects of culture in this developmental process.

Lastly, despite the aforemetioned limitations, this study makes an important contribution to this field of studies and to Brazilian Psychology by offering evidence that Brazilian children value close friendships. In addition, this study contributes to the study of prosocial lying, confirming data from recent psychological literature (Fu et al., 2007) showing the effects of culture on the use of prosocial lying in school children.

\section{References}

Bartsch, K., \& Wellman, H. M. (1997). Children talk about the mind. New York, NY: Oxford University Press.

Bergstrom, R., Najdowski, A. C., Alvarado, M., \& Tarbox, J. (2016). Teaching children with autism to tell socially appropriate lies. Journal of Applied Behavior Analysis, 49(2), 405-410. doi:10.1002/jaba.295

Bok, S. (1978). Lying: Moral choice in public and private life. New York, NY: Vintage Books.

Brewer, M. B., \& Chen, Y. R. (2007). Where (who) are collectivesincollectivism? Towardconceptualclarification of individualism and collectivism. Psychological Review, 114(1), 133-151. doi:10.1037/0033-295X.114.1.133

Ding, X. P., Gao, X., Fu, G., \& Lee, K. (2012). Neural correlates of spontaneous deception: A functional near-infrared spectroscopy (fNIRS) study. Neuropsychologia, 51(4), 704-712. doi:10.1016/j.neuropsychologia.2012.12.018

Ding, X. P., Sai, L., Fu, G., Liu, J., \& Lee, K. (2013). Neural correlates of second-order verbal deception: A functional near-infrared spectroscopy (fNIRS) study. Neuroimage, 87, 505-514. doi:10.1016/j.neuroimage.2013.10.023

Dunfield, K., Kuhlmeier, V. A., O’Connell, L., \& Kelley, E. (2011). Examining the diversity of prosocial behavior: Helping, sharing and comforting in infancy. Infancy, 16(3), 227-247. doi:10.1111/j.1532-7078.2010.00041.x

Eisenberg, N., Eggum-Wilkens, N. D., \& Spinrad, T. L. (2015). The development of prosocial behavior. In D. A. Schroeder \& W. G. Graziano (Eds.), The Oxford handbook of prosocial behavior (pp. 114-136). New York, NY: Oxford University Press.

Evans, A. D., Stolzenberg, S. N., Lee, K., \& Lyon, T. D. (2014). Young children's difficulty with indirect speech acts: Implications for questioning child witnesses. Behavioral Sciences \& the Law, 32(6), 775-788. doi:10.1002/bsl.2142

Ferreira, M. C., Fischer, R., Porto, J. B., Pilati, R., \& Milfont, T. L. (2012). Unraveling the mystery of Brazilian jeitinho: Acultural exploration of social norms. Personality \& Social Psychology Bulletin, 38(3), 331-344. doi:10.1177/0146167211427148

Fu, G., Heyman, G. D., Chen, G., Liu, P., \& Lee, K. (2015). Children trust people who lie to benefit others. Journal of Experimental Child Psychology, 129, 127-139. doi:10.1016/j.jecp.2014.09.006

Fu, G., Xu, F., Cameron, C. A., Heyman, G., \& Lee, K. (2007). Cross-culturaldifferencesinchildren'schoice, categorization, and evaluation of truth and lies. Developmental Psychology, 43(2), 278-293. doi:10.1037/0012-1649.43.2.278

Hamlin, J. K., Wynn, K., \& Bloom, P. (2007). Social evaluation by preverbal infants. Nature, 450(7169), 557-559. doi:10.1038/nature06288 
Heyman, G. D. (2013). Social evaluation. In M. R. Banaji \& S. A. Gelman (Eds.), Navigating the social world: What infants, children, and other species can teach us (pp. 62-68). New York, NY: Oxford University Press.

Imuta, K., Henry, J. D., Slaughter, V., Selcuk, B., \& Ruffman, T. (2016). Theory of mind and prosocial behavior in childhood: A meta-analytic review. Developmental Psychology, 52(8), 1192-1205. doi:10.1037/dev0000140

Kuhlmeier, V. A., Dunfield, K. A., \& O’Neill, A. C. (2014). Selectivity in early prosocial behavior. Frontiers in Psychology, 5, 1-6. doi:10.3389/fpsyg.2014.00836

Lavoie, J., Leduc, K., Crossman, A. M., \& Talwar, V. (2016). Do as I say and not as think: Parent socialisation of lietelling behaviour. Children \& Society, 30(4), 253-264. doi:10.1111/chso.12139

Lee, K. (2013). Little liars: Development of verbal deception in children. Child Development Perspectives, 7(2), 91-96. doi:10.1111/cdep.12023

Levine, R. V., Norenzayan, A., \& Philbrick, K. (2001). Cross-cultural differences in helping strangers. Journal of Cross-Cultural Psychology, 32(5), 543-560. doi:10.1177/0022022101032005002

Loke, I. C., Heyman, G. D., Itakura, S., Toriyama, R., \& Lee, K. (2014). Japanese and American children's moral evaluations of reporting on transgressions. Developmental Psychology, 50(5), 1520-1531. doi:10.1037/a0035993

Miller, S. A. (2019). Social-cognitive development in early childhood. In R. E. Tremblay, M. Boivin, \& R. D. Peters (Eds.), Encyclopedia on early childhood development. Retrieved from http://www.child-encyclopedia.com/ social-cognition/according-experts/social-cognitivedevelopment-early-childhood

Motta, F. C. P., \& Alcadipani, R. (1999). Jeitinho brasileiro, controle social e competição[Brazilianjeitinho, social control and competition]. Revista de Administração de Empresas, 39(1), 6-12. doi:10.1590/S0034-75901999000100002

Rabelo, A. L. A., Hess, M. A. G., \& Pilati, R. (2012). A moderação da prosocialidade entre o priming e a intenção de gentileza [The moderation of prosociality between the priming and the intention of kindness]. Psico, 43(2), 163-173. Retrieved from http://revistaseletronicas. pucrs.br/revistapsico/ojs/index.php/revistapsico/article/ view/11694/8040

Rakoczy, H., Warneken, F., \& Tomasello, M. (2008). The sources of normativity: Young children's awareness of normative structure of games. Developmental Psychology, 44(3), 875-881. doi:10.1037/0012-1649.44.3.875

Ross, H. S., \& Den Bak-Lammers, I. M. (1998). Consistency and change in children's tattling on their siblings: Children's perspectives on the moral rules and procedures of family life. Social Development, 7(3), 275-300. doi:10.1111/1467-9507.00068
Talwar, V., \& Lee, K. (2002). Emergence of white-lie telling in children between 3 and 7 years of age. Merrill-Palmer Quarterly, 48(2), 160-181. doi:10.1353/mpq.2002.0009

Wainryb, C., \& Recchia, H. (2014). Moral lives across cultures: Heterogeneity and conflict. In M. Killen \& J. G. Smetana (Eds.), Handbook of moral development (pp. 259-278). New York, NY: Psychology Press.

Warneken, F., \& Orlins, E. (2015). Children tell white lies to make others feel better. British Journal of Developmental Psychology, 33(3), 259-270. doi:10.1111/bjdp.12083

Wellman, H. M. (2014). Making minds: How theory of mind develops. New York, NY: Oxford University Press.

Winkielman, P., \& Schooler, J. (2009). Unconscious, conscious, and meta-conscious in social cognition. In F. Strack \& J. Forster (Eds), Social cognition: The basis of human interaction (pp. 49-70). Philadelphia, PA: Psychology Press.

Daiane Araujo de Arruda has a Master's degree in Psychology by Universidade Federal de São Carlos, São Carlos-SP, Brazil.

Debora Hollanda Souza, Ph.D., is an Associate Professor in the Psychology Department at Universidade Federal de São Carlos, São Carlos-SP, Brazil.

\section{Authors' Contribution:}

All authors made substantial contributions to the conception and design of this study, to data analysis and interpretation, and to the manuscript revision and approval of the final version. All authors assume public responsibility for the content of the manuscript.

Received: Jan. 30, 2018

1st Revision: Nov. 01, 2018

Approved: Nov. 10, 2019

How to cite this article:

Arruda, D. A., \& Souza, D. H. (2020). For whom is it worth lying? Prosocial lying in school children. Paidéia (Ribeirão Preto), 30, e3019.doi:http://dx.doi.org/10.1590/1982-4327e3019 